\title{
Drug Metabolism and Transport
}




\section{METHODS IN PHARMACOLOGY AND TOXICOLOGY}

Y. James Kang, DVM, PhD, SERIES EDITOR

Drug Metabolism and Transport: Molecular Methods and Mechanisms, edited by Lawrence Lash, 2005

Optimization in Drug Discovery: In Vitro Methods edited by Zhengyin Yan and Gary W. Caldwell, 2004

In Vitro Neurotoxicology: Principles and Challenges edited by Evelyn Tiffany-Castiglioni, 2004

Cardiac Drug Development Guide edited by Michael K. Pugsley, 2003

Methods in Biological Oxidative Stress edited by Kenneth Hensley and Robert A. Floyd, 2003

Apoptosis Methods in Pharmacology and Toxicology: Approaches to Measurement and Quantification edited by Myrtle A. Davis, 2002

Ion Channel Localization: Methods and Protocols edited by Anatoli N. Lopatin and Colin G. Nichols, 2001 


\section{METHODS IN PHARMACOLOGY AND TOXICOLOGY}

\section{Drug Metabolism and Transport}

Molecular Methods and Mechanisms

Edited by

\section{Lawrence H. Lash}

Department of Pharmacology

Wayne State University School of Medicine Detroit, MI 
(c) 2005 Humana Press Inc.

999 Riverview Drive, Suite 208

Totowa, NJ 07512

\section{www.humanapress.com}

All rights reserved. No part of this book may be reproduced, stored in a retrieval system, or transmitted in any form or by any means, electronic, mechanical, photocopying, microfilming, recording, or otherwise without written permission from the Publisher.

The content and opinions expressed in this book are the sole work of the authors and editors, who have warranted due diligence in the creation and issuance of their work. The publisher, editors, and authors are not responsible for errors or omissions or for any consequences arising from the information or opinions presented in this book and make no warranty, express or implied, with respect to its contents.

This publication is printed on acid-free paper. @

ANSI Z39.48-1984 (American National Standards Institute) Permanence of Paper for Printed Library Materials.

\section{Cover design by Patricia F. Cleary}

Cover illustrations: Ribbon representation of a human GSTZ subunit (foreground; Fig. 3, Chapter 4; see full caption and discussion on p. 92). Immunohistochemical localization of p65/RelA subunit of NF-KB transcription factor in sections from acetaminophen-treated liver tissue (background; Fig. 5, Chapter 8; see full caption on p. 212 and discussion on p. 211).

For additional copies, pricing for bulk purchases, and/or information about other Humana titles, contact Humana at the above address or at any of the following numbers: Tel.: 973-256-1699; Fax: 973-2568341; E-mail: humana@humanapr.com or visit our website: http://humanapress.com

\section{Photocopy Authorization Policy:}

Authorization to photocopy items for internal or personal use, or the internal or personal use of specific clients, is granted by Humana Press Inc., provided that the base fee of US $\$ 25.00$ per copy is paid directly to the Copyright Clearance Center at 222 Rosewood Drive, Danvers, MA 01923. For those organizations that have been granted a photocopy license from the CCC, a separate system of payment has been arranged and is acceptable to Humana Press Inc. The fee code for users of the Transactional Reporting Service is: [0-58829-324-6/05 \$25.00].

Printed in the United States of America. $110 \quad 9 \quad 8 \quad 8 \quad 7 \quad 6 \quad 5 \quad 4 \quad 3 \quad 2 \quad 1$

eISBN 1-59259-832-3

\section{Library of Congress Cataloging-in-Publication Data}

Drug metabolism and transport : molecular methods and mechanisms / edited by Lawrence H. Lash.

p. ; cm. - (Methods in pharmacology and toxicology)

Includes bibliographical references and index.

ISBN 1-58829-324-6 (hardcover : alk. paper)

1. Drugs-Metabolism. 2. Drugs-Physiological transport.

[DNLM: 1. Pharmaceutical Preparations-metabolism. 2. Biological

Transport—drug effects. 3. Drug Delivery Systems-methods. QV 38 D79363

2005] I. Lash, Lawrence H. II. Series.

RM301.55.D7625 2005

$615^{\prime} .7-\mathrm{dc} 22$ 


\section{Preface}

Two key aspects of how the body handles drugs and other chemicals are metabolism and transport. Metabolism is critical because it enables the body to process highly lipophilic molecules for further metabolism and eventual excretion, inactivates biologically active molecules, or detoxifies potentially toxic chemicals. Transport processes are critical because they determine the ability of drugs and other chemicals to gain access to sites of metabolism or to physiological or toxicological targets within tissues. The remarkable advances in molecular and cell biology and the development of novel in vitro model systems to study the various processes involved in metabolism and transport have expanded our knowledge and led to numerous, new therapeutic approaches to treatment of chemically induced toxicity and disease.

Drug Metabolism and Transport: Molecular Methods and Mechanisms, which is part of the Methods in Pharmacology and Toxicology series, presents a collection of chapters on selected aspects of metabolism and transport. The general approach of the chapters is to first present background on the topic to define the state of the science, to summarize key experimental models and methods that are used in the study of the process, and then to evaluate the utility of the various approaches and methods. Along the way, the various authors have endeavored to provide insight into why each model or approach is advantageous and discuss limitations and cautions in the application of these models or approaches. The goal here is not to provide step-by-step recipes for how to conduct specific assays, although selected procedures are outlined in some detail. Rather, the goal is to present some rationale for why certain models or approaches are used and to describe insight into how they are used to address various issues in drug metabolism and transport.

No single volume can address all the major metabolic and transport systems that handle drugs and other chemicals. However, this volume has selected several of the major drug metabolizing systems, including the cytochrome P450 family, flavin-containing monooxygenases, glutathione $S$-transferases, glucuronidation, $N$-acetylation, and sulfotransferases. Additional chapters present approaches to the study of signaling pathways in the regulation of drug metabolism enzymes, how modulation of thiols and other low-molecular-weight cofactors can alter drug metabolism, how 
one studies metabolism and toxicity of a prototypical toxicant, acetaminophen, and how modulation of drug metabolism pathways can influence antiviral therapy. Three chapters on transport are included to cover other very diverse processes: the multidrug-resistance proteins, the reduced folate carrier, and the plasma membrane and mitochondrial glutathione transporters. Many of the principles enunciated in these chapters can be applied to numerous other transport systems, so the present chapters serve as examples and prototypes.

Overall, the aim of Drug Metabolism and Transport: Molecular Methods and Mechanisms - by necessity only a partial survey of the drug metabolism enzymes and transporters-is to make clear the general principles and illustrate those approaches with wider application. Moreover, this compact reference is intended as a ready resource to investigators in their immediate work on either the specific processes the book describes or on other systems.

Lawrence H. Lash 


\section{Contents}

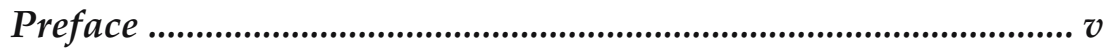

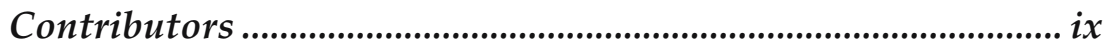

1 Renal Cytochrome P450s and Flavin-Containing

Monooxygenases: Potential Roles in Metabolism and Toxicity of 1,3-Butadiene, Trichloroethylene, and Tetrachloroethylene

Adnan A. Elfarra

2 Experimental Approaches for the Study of Cytochrome P450 Gene Regulation

Hollie I. Swanson, Susan D. Kraner, Soma S. Ray, Martin Hoagland, Earl D. Thompson, Xinyu Zheng, and Yanan Tian

3 Insulin and Growth Factor Signaling:

Effects on Drug-Metabolizing Enzymes

Sang K. Kim, Kimberley J. Woodcroft, and Raymond F. Novak

4 Catalytic Function and Expression of Glutathione

Transferase Zeta

Philip G. Board, M. W. Anders, and Anneke C. Blackburn ..... 85

5 Glucuronidation of Fatty Acids and Prostaglandins

by Human UDP-Glucuronosyltransferases

Anna Radominska-Pandya, Joanna M. Little, and Arthur Bull

6 Transcriptional Regulation of UDP-

Glucuronosyltransferases

Anna Radominska-Pandya, Peter I. Mackenzie, and Wen Xie

7 Phenotypic and Genotypic Characterization of $N$-Acetylation

Craig K. Svensson and David W. Hein

8 Methods and Approaches to Study Metabolism and Toxicity of Acetaminophen

Sam A. Bruschi 
9 Modulation of Drug Metabolism and Antiviral Therapies Bernhard H. Lauterburg 233

10 Modulation of Thiols and Other Low-Molecular-Weight Cofactors: Effects on Drug Metabolism and Disease Susceptibility

Charles V. Smith.

11 Multidrug Resistance Proteins and Hepatic Transport of Endo- and Xenobiotics

Phillip M. Gerk and Mary Vore

12 Structural Determinants of Folate and Antifolate Membrane Transport by the Reduced Folate Carrier Wei Cao and Larry H. Matherly

13 Glutathione Transport in the Kidneys:

Experimental Models, Mechanisms, and Methods

Lawrence H. Lash.

14 Human Cytosolic Sulfotransferases:

Properties, Physiological Functions, and Toxicology

Charles N. Falany.

Index 


\section{Contributors}

M. W. Anders • Department of Pharmacology and Physiology, University of Rochester, Rochester, NY

AnneKe C. Blackburn • Molecular Genetics, Division of Molecular Bioscience, Institute of Advanced Studies, The John Curtin School of Medical Research, Australian National University, Canberra, Australia

Philip G. BoARD • Molecular Genetics, Division of Molecular Bioscience, Institute of Advanced Studies, The John Curtin School of Medical Research, Australian National University, Canberra, Australia

SAm A. BRuschI - Department of Medicinal Chemistry, University of Washington, Seattle, WA

Arthur Bull $\bullet$ Department of Chemistry, Oakland University, Rochester, $M N$

WeI CAO $\bullet$ Developmental Therapeutics, Karmanos Cancer Institute and Department of Pharmacology, Wayne State University School of Medicine, Detroit, $M I$

Adnan A. Elfarra - Department of Comparative Biosciences, University of Wisconsin, Madison, WI

Charles N. Falany $\bullet$ Department of Pharmacology and Toxicology, University of Alabama at Birmingham, Birmingham, $A L$

PhILliP M. GERK • Graduate Center for Toxicology, University of Kentucky Medical Center, Lexington, $K Y$

David W. Hein • Department of Pharmacology and Toxicology, University of Louisville, Louisville, $K Y$

Martin Hoagland • University of Kentucky Medical Center, Lexington, $K Y$

SANG K. KIM • Institute of Environmental Health Sciences, Wayne State University, Detroit, $M I$

SusAn D. KRANER • Department of Molecular and Biomedical Pharmacology, University of Kentucky Medical Center, Lexington, KY

LaWrence H. LASH • Department of Pharmacology, Wayne State University, Detroit, $M I$ 
Bernhard H. Lauterburg • Department of Clinical Pharmacology, University of Bern, Bern, Switzerland

Joanna M. LitTle - Department of Biochemistry and Molecular Biology, University of Arkansas for Medical Sciences, Little Rock, AR

Peter I. Mackenzie • Department of Clinical Pharmacology, Flinders University, Bedford Park, Australia

Larry H. Matherly $\bullet$ Developmental Therapeutics, Karmanos Cancer Institute and Department of Pharmacology, Wayne State University School of Medicine, Detroit, $M I$

RAYMOND F. NovAK • Institute of Environmental Health Sciences, Wayne State University, Detroit, MI

AnNA RADOMINSKA-PANDYA $\bullet$ Department of Biochemistry and Molecular Biology, University of Arkansas for Medical Sciences, Little Rock, AR

Soma S. RAY $\bullet$ University of Kentucky Medical Center, Lexington, KY

Charles V. SMith • Center for Developmental Toxicology, Columbus Children's Research Institute, Columbus Children's Hospital; Department of Pediatrics, The Ohio State University, Columbus, $\mathrm{OH}$

Craig K. SvensSON • Division of Pharmaceutics, University of Iowa, Iowa City, IA

Hollie I. SWANSON • Department of Molecular and Biomedical Pharmacology, University of Kentucky Medical Center, Lexington, $K Y$

EARL D. THOMPSON - Department of Molecular and Biomedical Pharmacology, University of Kentucky Medical Center, Lexington, KY

YANAN TIAn • Department of Veterinary Physiology and Pharmacology, Texas A \& M University, College Station, TX

MARY VORE • Graduate Center for Toxicology, University of Kentucky Medical Center, Lexington, $K Y$

Kimberley J. Woodcroft • Institute of Environmental Health Sciences, Wayne State University, Detroit, MI

WEN XIE - Center for Pharmacogenetics and Department of Pharmaceutical Sciences, University of Pittsburgh, Pittsburgh, PA

XINYU ZHENG $\bullet$ Department of Molecular and Biomedical Pharmacology, University of Kentucky Medical Center, Lexington, $K Y$ 